\title{
Abschied vom Ost-West-Forum
}

\section{In eigener Sache}

\section{Michael Ermann}

Online publiziert: 6. September 2016

(C) Springer-Verlag Berlin Heidelberg 2016

Als 1989 die Berliner Mauer gefallen und die Barrieren an der innerdeutschen Grenze abgeräumt waren, entstand auch ein reger Austausch zwischen den ost- und westdeutschen Psychoanalytikern. Es war unser verstorbener Kollege Carl Nedelmann, der selbst an diesen Begegnungen mit großem Engagement beteiligt war und sie zum Anlass nahm, in dieser Zeitschrift ein „Ost-West-Forum“ einzurichten. Es sollte sowohl die Dynamik dieser Begegnungen reflektieren als auch die Erfahrungen vor allem der ostdeutschen Kolleginnen und Kollegen im Erleben und in der Verarbeitung der sogenannten Wende unter psychoanalytischer Perspektive. So entstand über die Jahre eine Serie von Beiträgen, die bei unseren Lesern auf viel Interesse stieß.

Inzwischen ist die deutsche Einheit zum Alltag geworden, und auch der Zufluss von Beiträgen für das Ost-West-Forum versiegt. Wir haben deshalb entschieden, mit dem nachfolgenden Beitrag das „Ost-West-Forum“ zu beschließen und Beiträge zu diesem Thema künftig als „Originalarbeiten“ zu veröffentlichen. An dieser Stelle gilt unser Dank Carl Nedelmann für die jahrelange Betreuung dieser Rubrik.

Prof. Dr. med. M. Ermann ( $ه)$

München, Deutschland

E-Mail: Ermann-Forum@t-online.de 